\title{
EXPLORING THE RELATIONSHIP BETWEEN MOBILE DATA SERVICES BUSINESS MODELS AND END-USER ADOPTION
}

\author{
Per E. Pedersen ${ }^{1}$ and Leif B. Methlie ${ }^{2}$ \\ ${ }^{1}$ Agder University College, Grooseveien 36, 4896 Grimstad, Norway; ${ }^{2}$ Norwegian School of \\ Economics and Business Administration, Breiviksveien 40, 5045 Bergen, Norway
}
Abstract: $\quad$ Adoption of mobile data services may be analyzed within the framework of two-sided markets. Service or content providers should adopt platforms for developing, integrating and distributing mobile services and end-users should adopt the offered services as well as the user platform offered. These two mar- kets are often analyzed separately using different theoretical perspectives and models. In this article, we propose a model for integrating the two sides of the mobile data services market. The model is used to propose relationships be- tween dominant actors' choice of business models for individual services and the end-users' perceived value of these services.

Key words: business models; mobile data services; adoption; user acceptance; strategy; governance form; customer value; network effects.

\section{INTRODUCTION}

Recent analyst reports and academic papers suggest that open, collaborative business models are required to obtain variety in service offerings and consequently adoption of service platforms as well as end-user services. The authors most often refer to the Nordic experience with the so called CPAmodels (Content Provider Access) for SMS and MMS services (Strand Consult, 2002, Northstream, 2002). However, this open model has not been equally successful in providing WAP services in these countries. Furthermore, recent examples suggest that closed, vertically integrated business 
models have been successful when introducing the more advanced mobile data services likely to be expected in 3G networks. Examples are the semiwalled garden model of DoCoMo's I-mode services in Japan and the model applied by Vodafone to provide their "Live!" services. Thus, it seems that examples of both successful and less successful service introductions may be found applying both closed and open business models.

While the conceptual dimensions of business models have recently obtained considerable attention (Camponovo and Pigneur, 2003; Faber et al., 2003, Bouwman, 2003), dominant actors' choice of specific business models and the relationship between these decisions and firm or service performance have been less attended to. End-users perception of intrinsic service attributes has also obtained considerable attention in resent research on the adoption of mobile data services. However, research on the perception of extrinsic service attributes, such as end-user network size and complementary service variety has mainly been focused in contexts of professional end-users and traditional computer contexts, such as operating systems.

The purpose of this paper is to extend research on the conceptual dimensions of mobile services business models into explorations of the relationship between business model dimensions and performance. In this paper, performance is discussed in the context of the perceived and anticipated value of the services offered. In the next section, we review some of the literature and recent empirical studies on mobile services business models, mobile services attributes and end-user adoption. In section 3, a model of the relationship between these elements is presented. In section 4 , we present a set of propositions that emerge from this model, and in section 5 we conclude and discuss how to use this model for service analysis and empirical research.

\section{THEORY}

Explanations of mobile data services success span from focusing specific factors, such as the lack of an appropriate revenue model (Foros et al., 2001) to suggesting general systemic explanations, such as the dynamics of industry ecosystems (Vesa, 2003). The most common approach, however, is to combine a set of technological, business strategic and behavioral or cultural factors. For example, Henten et al. (2003) suggest technology, economy, market development and structure, marketing, socio-cultural, policy intervention and regulation as the relevant explanatory factors. Pedersen (2001) suggested three general requirements for successful adoption of mobile data services; technology-, business strategic-, and behavioral requirements. Some authors apply a comparative perspective analyzing differences in 
adoption between Asian and European markets. For example, Bohlin et al. (2003) compare the developments of mobile data services in Japan and Europe and oppose popular assumptions that differences in adoption rates may be explained by differences in technology, regulatory regimes, cultural differences, Internet penetration and differences in consumer segments focused in marketing. Instead, they suggest the important differences are the coordinated and vertically integrated service concepts and the revenue models offered by Japanese operators. Our focus is on the integrating role of business models and behavioral factors. We suggest that the choice of specific business models by dominant actors is one of the most important explanations of mobile data services success.

\subsection{Business models}

The term business model has been used mostly in traditional electronic commerce. One of the first contributions came from Timmers (1998) suggesting that a business model describes the architecture for the product, service and information flows, including a description of various business actors and their roles, a description of potential benefits for the various actors, and a description of the sources of revenue. Thus, it includes infrastructure, value proposition and financial dimensions. Similarly, Weil and Vitale suggest that a business model is the "description of the roles and relationships among a firm's consumers, customers, allies and suppliers that identifies the major flows of products, information and money, and the major benefits to participants" (Weill \& Vitale, 2001, p. 34). Methlie and Pedersen (2002) included three operational dimensions in their business model concept; integration model, collaboration model and revenue model. They focus that individual providers' business model options are restricted by structural determinants and value network considerations because value creation in both traditional and mobile electronic commerce requires a shared understanding of the business model of each network member. In some industries the business models options of each value network member are indirectly determined by the business model of the dominant members (e.g. operators in some mobile services industries and operating system developers in the software industry). Recently, several authors have applied the business model concept to mobile commerce and mobile data services contexts (Camponovo and Pigneur, 2003; Faber et al., 2003, Bouwman, 2003). With some variations in propositions, these authors mainly suggest four dimensions of business models; the product innovation, the customer relationship, the infrastructure and the financial dimensions, covering the product related value proposition, the customer related value proposition, the structural dimension and the revenue dimension, respectively (e.g. Camponovo and 
Pigneur, 2003). However, the choice between specific options along these dimensions and the performance effects of choosing specific options under different structural conditions have been given less attention in this literature. Instead, performance effects of the choice of options for product-, customer-, financial- and infrastructural business model dimensions are treated separately in individual research areas such as product innovation, industrial organization and strategic marketing. Thus, integration is necessary to apply this research to a specific industry like the mobile data services industry. It is beyond the scope of this paper to integrate and apply the vast literature on the performance effects of business model options to the mobile data services industry. However, it is well documented in this literature that the choice of a specific business model affects the intrinsic and extrinsic attributes of the product developed or produced (Nicholls-Nixon and Woo, 2003; Zahra and Nielsen, 2002; Sengupta, 1998; Stuart, 2000).

\subsection{Customer value}

Service attributes emerge from two different sources. Intrinsic attributes refer to the inherent attributes of the service itself, whereas for network goods, extrinsic attributes emerge from the networks that provide and use the service. This involves an extension of the traditional typology of intrinsic and extrinsic sources of value suggested by Holbrook (1996), and underlines how network services are different from traditional products and services where extrinsic attributes often originate from supplier services and consumer investments (Mathwick, Malhotra and Rigdon, 2001). The two types of attributes represent the sources of intrinsic and extrinsic value unique to network effects products as suggested by Lee and O'Connor: "extrinsic value... is unique to network effects products... is the set of benefits derived from outside the product itself, such as the size of the installed base and the availability of compatible and complementary products..." (Lee and O'Connor, 2003, p. 244).

Many unique intrinsic attributes have been mentioned characterizing mobile services. One of the most obvious characteristics of mobile services is the lack of constraints related to time and space (Balasubramanian, Peterson, and Jarvenpaa, 2002). Watson, Pitt, Berthon, and Zinkhan (2002) suggest the "U-commerce" construct to describe services characterized by ubiquitous-, universal-, and unison access as well as uniqueness. Doyle (2001) suggests the following key characteristics of SMS: personal, real time delivery, unobtrusive, low price, simple, supports two way communication, can be forwarded, and location based potential. Thus, being personal seems to be an additional intrinsic attribute of mobile data services (Siau, Lim, and Shen, 2001). This corresponds well to the suggestions by Kannan, Mei Chand, and 
Whinston (2001). They argue that wireless devices are accessible, personal and location aware, and thus, that these attributes are unique to mobile services.

A problem with considering accessibility and "being personal" as unique attributes of mobile services is that these attributes are general and unrelated to the content of the mobile service. Even though the lack of constraints related to time and space of mobile services has been suggested as the basis for their usefulness (Pedersen and Nysveen, 2003), usefulness is mainly determined by the content of the service - its functionality. Often, the usefulness of mobile services depends on other users using it rather than the accessibility or personalization attributes of the service. This is particularly true for communication or person-interactive services, where extrinsic attributes are more important for creating customer value than the intrinsic attributes of the service. Still, for information or machine-interactive services, the usefulness of the service is an important intrinsic attribute (Pedersen and Nysveen, 2003). A unique intrinsic attribute found important in six studies of mobile service adoption by Nysveen, Pedersen and Thorbjørnsen (in press) was enjoyment. Even for services with functionality that in principle was unrelated to enjoyment, such as mobile payment services, enjoyment was found to be an important intrinsic attribute (Pedersen and Nysveen, 2003). This finding corresponds well to studies of mobile services in uses and gratification research suggesting that gratifications of "relaxation" (Leung and Wei, 2000) and "nutz-spaz" (Höflich and Rössler, 2001) are important to the adoption and use of mobile services. Intrinsic attributes of a service may also be described by technical specifications, for example related to speed and capacity. It is difficult to determine such attributes for services in general, and mobile services are no exception. Still, attributes such as network bandwidth, dial-up speed, coverage and signal strength have been suggested. For example, in a service quality framework for mobile services, Nordman and Liljander (2003) suggested dial-up speed and configuration settings as important components of service quality.

A study by Ling (2001) shows that mobile phones are used to express fashion and social identity. Other results also indicate that mobile devices and services are used to express and confirm the users' personal identity (Pedersen and Nysveen, 2003). These symbolic and expressive attributes of mobile services are mainly extrinsic attributes because they result from the service being used in a network context. The two most often mentioned extrinsic attributes of network goods are direct and indirect network effects. Direct network effects are the effects related to increasing value of a service as the size of the network increases (Liebowitz and Margolis, 1999). Network effects are typical of all communication and person-interactive mobile services and have been the basis for understanding value propositions and 
the choice of governance forms in telecommunication networks. In their study of 125 value added services, Brosseau and Quelin (1996) found that communication and information services were provided applying systematically different governance forms.

While direct network effects are important extrinsic attributes of communication services, indirect network effects are more often focused in information, transaction or machine-interactive services. Indirect network effects originate from direct network effects when the networked good is a platform for complementary services and products (Gupta, Jain and Sawhney, 1999). Mobile data services differ with respect to their potential as a platform for complementary services. For example for information and machineinteractive services like premium SMS, mobile Internet access or game services, the potential for generating indirect network effects is great. From indirect network, a set of operational extrinsic service attributes, such as complementary service variety, speed of complementary service development and complementary service quality may be identified. As for direct network effects, considerable attention has been given to the importance of indirect network effects in consumers' assessment of service or product value. For example, researchers in economics, marketing and information systems have concluded that the availability of complementary goods affects the prices that can be obtained for networked goods (Gandal, Kende and Rob, 2000; Basu et al., 2003; Brynjolfsson and Kemerer, 1996).

Recently, end-users perception of network effects has been given considerable attention. Studies of innovation adoption take sensitivity to network effects into consideration and argue that network size is more important when the network is small than when it is large. This suggests that adoption likelihood is sensitive to critical mass and anticipation of future network size (Shapiro and Varian, 1999). For example, the use of pre-announcement and commitment announcements are examples of strategies used to convince end-users that future network size is expected to be large and that it will increase quickly (Lee and O'Connor, 2003; Montaguti, Kuester and Robertson, 2002). Perceptions and anticipation of direct network effects have also recently achieved considerable attention in information systems, strategy and marketing literature (Gallaugher and Wang, 2002; Schilling, 2003; Frels, Shervani and Srivastava, 2003). Most of these studies have been conducted in professional end-user markets suggesting that direct network effects are taken into consideration in professional end-users' value assessment process. We are unable to identify similar research in traditional consumer markets. However, economic theory on network effects assumes that consumers are somehow able to make such assessments and includes network size elements in consumers' utility functions (e.g. Katz and Shapiro, 1992; Foros, 2003). For indirect network effects, end-users' appreciation of complementary ser- 
vice variety and innovativeness may also vary across user segments. For professional consumers, it is likely that complementary service variety is assessed and appreciated (Frels et al., 2003). For simple consumer network goods where the complementary goods are content goods delivered on a content distribution platform such as a video game platform, this is also very likely (Schilling, 2003). However, for complex or radically new network goods like mobile data services, the assessment and valuation of indirect network effects are much more difficult. In this case, consumers will often also have to assess the value of future indirect network effects as a consequence of adopting the network goods platform. This is an even more difficult task requiring considerable experience or cognitive capacity.

From this selective and brief review of some of the recent research on business models, service attributes and service adoption in mobile services markets we suggest that the relationships between these elements may be explained by a research model where options along specific business model dimensions are operational, relevant intrinsic and extrinsic service attributes are specified, and knowledge of end-users' perceptions of service attributes are moderated.

\section{MODEL}

The proposed model follows the structure-conduct -performance (SCP) framework often applied in empirical industrial organization (Kadiyali, Sudhir and Rao, 2001). Structural determinants, however, have been focused elsewhere (Gressgård, Methlie and Stensaker, 2003) and the conductperformance relationship is focused here. The model is illustrated in figure 1. In the model, we propose that specific business model dimension options affect the intrinsic and extrinsic service attributes as well as end-user characteristics. Furthermore, we propose that the relationship between service attributes and perceived and anticipated value is moderated by end-user characteristics. While the literature cited in section 2 was general with respect to business model dimensions, service attributes and end-user value perceptions, a research model will have to be more operational for these concepts to be useful in hypothesis development.

The business model concept has been operationalized along three dimensions. For the financial arrangement dimension found in the business model ontology literature we focus on the revenue model including revenue valuation and sharing. Content based valuation means that end-users pay per unit of the service content delivered, whereas transport based valuation means that end-users pay for the amount of time online, packet charge or similar volume units. The revenue share element may have a complex option struc- 
ture, but we simplify this to revenue shares favoring content rather than transport. A content oriented revenue share involves a relatively larger proportion of revenue is redistributed to content providers, whereas a transport oriented revenue share involves a relatively larger proportion of revenue is redistributed or retained by network or transport providers. In almost all practical settings, the objects of revenue valuation and sharing are equivalent. Consequently, we apply the dichotomy of content versus transport oriented revenue models here.

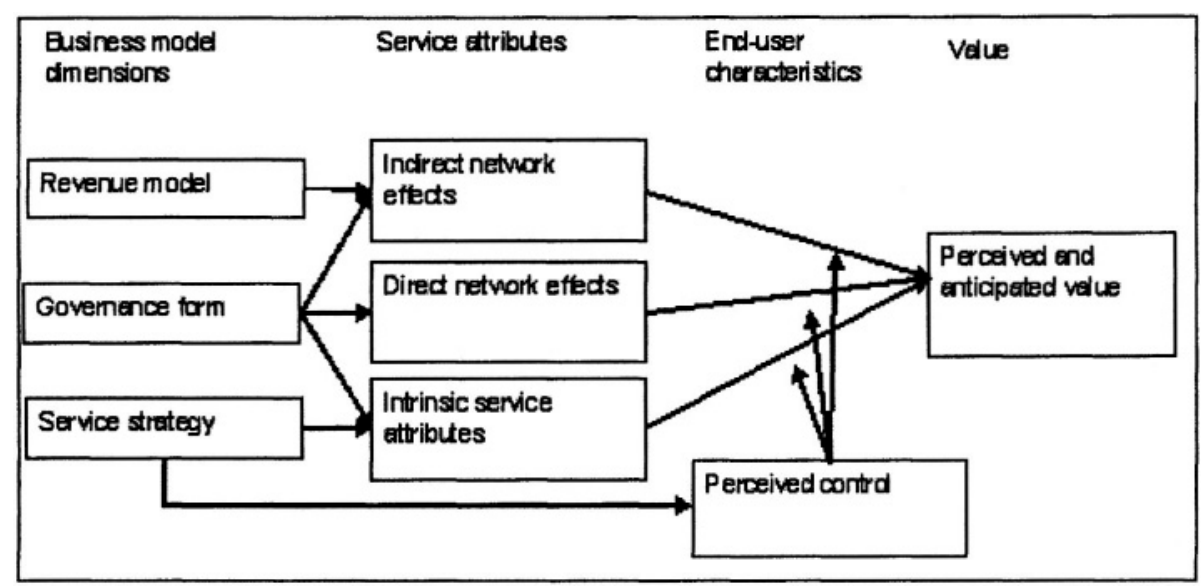

Figure 1. Research model

For the infrastructural arrangement dimension, we focus on governance form corresponding to governance form or mode as treated in new institutional economics and organization theory. Providers' options further correspond to the traditional categorization of governance forms as market, relational and hierarchy modes or forms (e.g. Ghosh and John, 1999). However, governance form is a complex element, and it may include several options. We have previously suggested that the relational form of governance includes so many options that it may be treated as a separate element in the infrastructure dimension of a providers' business model (Pedersen, 2001). For example both network forms and alliance forms are relational forms, but there is little doubt that these forms may have quite distinct and different effects on service attributes and thus, performance.

The product innovation and customer relationship dimensions may be treated under the common term service strategy with two elements including 
service value proposition ${ }^{6}$ and market focus elements corresponding to Porter's (1985) generic strategy elements. The options for the service value proposition element are service dependent and related to the specific gratifications of the mobile data service investigated applying the model. We have discussed some of these gratifications above but here we focus two important option issues. The first is to what degree the value proposition focuses the unique attributes of mobile services. Examples are accessibility that only may be obtained through the mobile device or personalization that is unique due to identification of the end-user. The second option issue is that of breadth in service attribute offerings. Examples are services that cover a large set of mobile service gratifications versus services that cover a focused set of gratification as part of their value proposition. Thus, we suggest the two options of mobile-specificity (uniqueness) and proposition breadth (scope). For the market focus element we apply the focused versus undifferentiated options of Porter (1985).

In principle, all these options may be treated as continuous. For example, the choice of governance form is not a discrete choice between market, relational and hierarchy forms. Instead, the options vary with respect to the degree that hierarchical, relational and market oriented governance mechanisms or processes are included (Heide, 1994). Thus, closed business models include governance mechanisms of the hierarchical form whereas open models include governance mechanisms of the relational and market forms. Similarly, revenue share options involve a choice of the revenue share redistributed to content provider rather than an absolute value above or below $50 \%$ indicating a content versus transport oriented model.

As suggested in section 2, mobile data services attributes are categorized as intrinsic reflecting inherent attributes of the service itself, or extrinsic reflecting direct and indirect network effects. For indirect network effects we suggest that the attributes of the complementary services network include complementary service variety, -quality and speed of development. For $d i$ rect network effects we suggest that the attributes are related to end-user network size and speed of diffusion. While several intrinsic attributes were discussed in section 2, we suggest mobile specific usefulness, service quality, ease of use and interoperability ${ }^{7}$. Intrinsic attributes may also be specific to the service category being investigated, and thus, other intrinsic service attributes may be focused for example for goal-oriented versus experiential

${ }^{6}$ The terms "positioning" and "positioning option" are often used in marketing strategy literature (e.g. Ghosh and John, 1999)

${ }^{7}$ Ease of use and interoperability may be included in the service quality concept if applying a framework similar to SERVQUAL for mobile services (Nordman and Liljander, 2003). 
service categories. For the moderating factor termed end-user characteristics in figure 1, we focus perceived control. The term is often used in information systems adoption literature (e.g. Taylor and Todd, 1995) to reflect the combination of end-users perceptions of their own resources (e.g. skills, experience, financial) and facilitation of the service provider. The model is based on rationalistic assumptions suggesting that end-users adopt mobile data services with high perceived and anticipated value. Value perceptions reflect the value assessments that are made from current intrinsic and extrinsic service attributes whereas anticipated value reflects expectations of further development of these attributes. In figure 1, intrinsic and extrinsic attributes are unrelated, but for many mobile services these attributes are related. Still, because such relationships are service specific, the general model in figure 1 initially propose that service attributes are unrelated. However, this proposition may be modified for service specific versions of the model.

The relationships in the model illustrate the main influences from the choice of business model options on service attributes and the main and moderated influences from these attributes on perceived and anticipated value. We suggest that the choice of revenue model primarily influences the complementary service attributes of mobile data services, in particular if the mobile data services offered represent service platforms (e.g. SMS, MMS or WAP). Governance form is expected to influence both extrinsic and intrinsic attributes. For example, hierarchical governance forms are likely to give service developers full control of the intrinsic attributes of a service and the attributes of its complementary services. Furthermore, if the firm applying this form is large, it may utilize its installed base to obtain speed of diffusion in new service domains. The choice of a particular service value proposition is the most influential factor determining the intrinsic attributes of a service, whereas the choice between a focused or an undifferentiated market strategy is likely to affect whether end-users have the necessary experience or skills to perceive behavioral control of the mobile service being used.

The relationship between service attributes and end-user value includes two sets of influences. The first set is the main effects of service attributes on perceived and anticipated value. In the second set, we assume that these relationships are moderated by the perceived behavioral control of end-users. For example, one may propose that complementary service variety leads to high perceived value for all users, but one may also propose that this is only true for experienced end-users being able to utilize and choose among these services. Less experienced end-users may be confused by a great variety of complementary service offerings. 


\section{PROPOSITIONS}

As can be seen from figure 1, two sets of propositions may be suggested: A) Propositions on the relationship between business model options and service attributes, and B) propositions on the relationship between service attributes and perceived and anticipated value. In section 3, we suggested the two most relevant financial dimension elements of the business model to be revenue share and valuation object. In almost all empirical settings, the objects of revenue valuation and sharing are equivalent. Thus, the same theoretical arguments may be given for both elements of the revenue model dimension. We suggest that revenue share models may be categorized according to their implicit appreciation of content versus transport. Because the value network for mobile data services involves complementary services, we assume that complementary service variety, quality and speed of development will be obtained by stimulating the providers of these services. Consequently, pricing and revenue sharing become parts of the innovation process of network and platform providers (Jonasson, 2001). There are many ways to design the revenue models that stimulate the providers of complementary services. For example, economists have discussed the use of different forms of subsidizing in two-sided markets to obtain profit in the base (e.g. platform) market and stimulate competition in the other (e.g. content provider) market (see e.g. Armstrong, 2002). However, complementary service providers will be able to assess the degree of competition in the complementary service market making them reluctant to innovate if this strategy is used aggressively by the network or platform providers to obtain monopoly profits. Another issue is that network or platform providers may use access costs as an instrument in regulating service providers' access to the network or platform (Rochet and Tirole, 2002; Foros, Kind and Sørgard, 2002). We assume that mobile data services markets have a two sided structure where platform or network providers recognize the need to stimulate innovation in complementary services and that revenue sharing in some form contributes to this. Thus, we suggest that regardless of the use of subsidizing, access pricing or other strategy for regulating content or service providers access to the network or platform, complementary service providers will be stimulated better if platform providers' offer transparent and content/service based revenue models. For example, if a mobile operator uses a content based revenue object, the revenue sharing model will be based upon this revenue object and providers of complementary services will have a simple model that makes it easer for them to assess the potential revenue from accepting operators' business model and adopting their service provisioning platform. Thus, we propose: 
Ala-c: Using content oriented revenue models increases complementary service variety, quality and speed of development.

The element of the infrastructure dimension that we have focused is governance form. We suggested categorizing the governance form in market, relational and hierarchy forms. We also suggested that the hierarchy versus relational and market forms represent a continuum rather than a discrete categorization of governance forms. Still, we maintain the original option categorization here and propose:

A2a-b: Using relational and market governance forms increases complementary service variety and speed of development.

The arguments behind this proposition were discussed in section 2. In particular, literature on governance forms in network markets as well as resource based theory suggest that complementary service variety and diversity is better obtained using open forms of collaboration (e.g. Schilling, 2003). Zahra and Nielsen (2002) found that relational forms increased development speed. In addition, when involvement and formal coordination were included as moderators, market forms of governance also increased development speed. Service quality on the other hand, may come out of the service integrator's control or service quality may not be related to perceived quality elements when governance is left to market or relational forms (Dyer and Singh, 1998; Ghosh and John, 1999, p. 137). Thus, we propose:

A2c: Using hierarchical governance forms increases complementary service quality.

Governance form is also expected to influence direct network effects. For example, Frels et al. (2003) found that professional consumers where able to assess direct network effects through the strength of the user network of operating systems. Gallaugher and Wang (2002) suggested mindshare was an important proxy used by professional consumers to assess future direct and indirect network effects. We suggest that firm size is a moderating variable in the relationship between governance form and direct network effects in that size is required to make the hierarchical governance forms trigger direct network effects in the form of end-user network size and speed of diffusion. Thus, we propose:

A3a-b: For larger firms hierarchical governance forms increase enduser network size and speed of diffusion.

Finally, governance form is expected to influence intrinsic attributes of the individual service offered through a provider's business model. From the product innovation literature cited in section 2 we also suggest that innovativeness is promoted both in the complements and platform markets through the use of relational and market governance forms. Also, a study by Srinvasan, Lillien and Rangaswarny (2002) found that a hierarchy culture was negative related to technological opportunism whereas an adhocracy culture 
was positively related to technological opportunism ${ }^{8}$. Because these culture forms were derived from governance forms, the findings support the following proposition:

A4a: Using relational and market governance forms make providers able to offer more innovative, useful services.

On the other hand, relying on relational and market forms of governance may make platform providers and individual service providers lose control of the production and distribution process of their service. Furthermore, internal interoperability and intrinsic quality may not be obtained by relying on standards that may be interpreted differently by different providers collaborating using relational and market forms of governance. For example, Sahay and Riley (2003) found that vertical integration lead to increased focus on customer interface standards, but they found no support for their proposition that vertical integration lead to less focus on compatibility standards. Thus, relying on transaction cost theory, we suggest:

A5a-b: Using hierarchical governance form increases the ease of use, interoperability and intrinsic service quality.

In section 3, we suggested two elements of relevance to value proposition; service value proposition and market focus. For the service value proposition element we suggested the issue of mobile specificity (uniqueness) and breadth (scope) of offerings to be important. We suggest that the potential for creating higher value among end-users is greater when the service offerings are mobile specific. This means that the services are designed to meet the unique gratifications expected from mobile services. Thus, we propose that this will be reflected in the potential ease of use, usefulness and quality of the service. Thus, we propose:

A6a-c: Mobile-specific value propositions increase ease of use, usefulness and intrinsic service quality.

Mobile specificity may require focusing the service offering, but research shows that a variety of gratifications is expected from mobile data services (Leung and Wei, 2000; Nysveen, Pedersen and Thorbjørnsen, in press). However, trying to fulfill a variety of gratifications may result in more complex services with less mobile specific usefulness and service quality. Thus, we suggest:

A6b-c: Value propositions with greater breadth reduce intrinsic service quality, ease of use and usefulness.

${ }^{8}$ For opposite arguments, see the discussion on new product development in integrated firms and responsiveness (e.g. Richardson, 1996) and the "incumbent's curse" discussion (Chandy and Tellis, 2000) 
For market focus, we suggested applying the traditional categorization of focused versus undifferentiated strategies from Porter (1985). In general, a focused strategy makes it easier for the provider to adapt their services to the requirements and qualifications of end-users. We suggest that the successful adaptation is reflected in the perceived control of end-users. Perceived control is assumed to be influenced by experience, resources and end-users' self-efficacy. In general, we suggest that due to a better adaptation of services to experience, resources and skills:

A7a: Using focused market strategies increases perceived control.

The next set of relationships in the model illustrated in figure 1 is the set of relationships between service attributes and perceived and anticipated value of end-users. We first suggest a set of propositions on these direct relationships. Next, we suggest how perceived control is likely to moderate these relationships. While research in economics indirectly assumes network effects are perceived and anticipated, behavioral research in marketing and strategy is not so conclusive on this matter. While several studies have shown that the availability of complementary goods increases the perceived value of the platform good (e.g. Basu, Mazumdar and Raj, 2003), Cottrell and Kaput (1998) also showed that the variety of complementary goods increase platform value. However, research suggests that consumers appreciate variety and quality differently, and that there may be product and service differences in the appreciation of variety versus quality. For example, Bohlman, Goldman and Mitra (2002) investigated the survival of pioneers and found that pioneers did better in product categories where variety was important and worse in categories where product quality was important. Still, for the complementary service attributes variety, quality and speed of development, we suggest:

Bla-b: Complementary service variety, quality and speed of development increase perceived value.

and

B1c: Complementary service speed of development increases anticipated value.

Direct network effects attributes are service dependent, complicating the assessment of the end-user value of these attributes. However, we assume a minimum degree of direct network effects and focus on attributes reflecting direct network effects that are not specific to any particular mobile data service category. In general, the rate of which a networked service is adopted by users is expected to increase end-user value because critical mass will be reached earlier. Also, when anticipating future value, end-users process information under the assumptions of bounded rationality. Using heuristic judgment, it is likely that current network size is used as a proxy for future network size (Tversky and Kahneman, 1974). Thus, we suggest: 
B2a-b: Increasing speed of diffusion and network size increase perceived and anticipated value.

Our proposed relationships between intrinsic attributes of mobile data services and perceived value focus the specificity and variety of gratifications sought by end-users. We argue that gratifications obtained should be mobile specific and because end-users seek a variety of gratifications from mobile services, richness in service attributes is also appreciated. Thus, we suggest the following propositions:

B3a-d: Mobile-specific usefulness, ease of use, interoperability and greater service quality increase perceived value.

While it may be argued that there are direct effects of service attributes on perceived and anticipated value of mobile data services, it is even more likely that this relationship is moderated by the perceived control of endusers. For example, resources in the form of both monetary resources and skills make it more likely that end-users having these resources have explored and tested a variety of data services, and that they are better qualified in making assessments of value based upon such trials. For example, Herpen and Pieters (2002) found that both preference awareness (negatively) and expertise (positively) moderated the relationship between assortment variety and preference. Thus, we suggest three propositions where perceived control positively moderates the relationship between service attributes and perceived and anticipated value.

B5a-c: Perceived control positively moderates the effect of complementary service variety, speed of development and speed of diffusion on value.

The other propositions on moderating effects assume that the relationship between service attributes and value is moderated negatively by perceived control. For example, users with little experience in using mobile data services will appreciate ease of use more than experienced users. The moderated influence of network size, on the other hand, is difficult to decide. Users with considerable perceived control are likely to be sensitive to network size, but these users may use other measures of current and future network size than currently observed size. Thus, we suggest five propositions on the moderated relationship between service attributes and value:

B6a-e: Perceived control negatively moderates the effect of complementary service quality, network size, ease of use interoperability, and intrinsic service quality on value.

In an empirical study it is impractical to investigate the large number of propositions suggested here. From this exploratory investigation, the number of relevant propositions needs to be reduced and directions for empirical research must be further specified. 


\section{CONCLUSIONS AND FURTHER RESEARCH}

We have presented a model suggesting that business model decisions influence end-users' perceived and anticipated service value through the intrinsic and extrinsic service attributes they promote. From the model, a set of propositions emerges that may be investigated empirically. However, the model may also be used for analytical and normative purposes if it is validated empirically.

From our experience with using the model for analytical purposes, we suggest that many studies of mobile data services success investigate services at an insufficient level of detail. We may illustrate this by applying the model to an analysis of the mobile payment service of Telenor, the largest Norwegian mobile operator. Its payment service, Mobilhandel ${ }^{\mathrm{TM}}$, may be used to pay for a variety of services, content and products. Still, mobile payment services are often analyzed as one service category with one set of service attributes without discussing their richness of functionality. In the case of Mobilhandel ${ }^{\mathrm{TM}}$, the service may be used to pay for products and services at the point-of-sales, to pay money to other users, or to recharge users' prepaid phone cards. It is obvious that the intrinsic and extrinsic attributes of these service functionalities are very different. At the point-of-sales, endusers will appreciate that a large number of merchants accept the payment solution. Thus, the variety of the complementary service network is the most important attribute of this functionality. To pay other people, the size of the network of Mobilhandel ${ }^{\mathrm{TM}}$ users is of most importance, so that end-users can pay anyone using the service just as they use cash. Finally, the most successful functionality of the service, representing more than $80 \%$ of current transaction volume, is recharging end-users' own or other mobile phone users' prepaid card. This is a functionality that is unrelated to network size and its perceived value is only influenced by whether it is considered useful and easy to use. The conclusions that may be drawn from this example are that the three functionalities of the service may be offered to end-users applying three different business models promoting indirect network effects in the first case, direct network effects in the second, and controlling intrinsic service attributes in the final case. This also corresponds well to the suggestions of Brousseau and Quelin (1996) concluding that "the success of an information-intensive service is based on its intrinsic quality... there are no network externalities ... therefore, when possible, a single firm should seek to become a core firm" (Brousseau and Quelin, 1996, p. 1223.

To validate the model, empirical research is required. Because the model uses service attributes as the key intermediary concepts linking business model decisions and end-user value, empirical investigations should investigate the business models and end-users' perceived value of services with 
contrasting intrinsic and extrinsic service attributes. For example, communication services appreciated for their end-user network size should be compared to content services appreciated for their complementary service variety along two dimensions. The first is how business model decisions promote appreciated service attributes in each case, and the other is how end-users assess the value of these attributes. Other examples of such comparative service categories are gaming versus dating services. Both services are appreciated for their intrinsic attribute of enjoyment, but the value of dating services depend directly on network size whereas the perceived value of gaming services only indirectly depend on end-user network size through indirect network effects. These examples illustrate the two directions our future research will take. First, we survey mobile data services offerings to categorize services according to intrinsic and extrinsic service attributes. Second, we design two sets of empirical studies investigating, 1) the business models applied to promote the unique intrinsic and extrinsic service attributes believed to be important for each of these service categories, and 2) the valuation process of end-users explaining how these unique attributes affect perceived and anticipated value as well as how this process is moderated by behavioral control.

\section{REFERENCES}

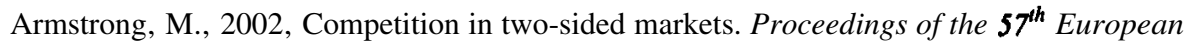
Meeting of the Econometric Society, Venice, Italy, August 25.28.

Balasubramanian, S., Peterson, R. A., and Jarvenpaa, S. L., 2002, Exploring the implications of M-commerce for markets and marketing. Journal of the Academy of Marketing Science, 30: $348-361$.

Basu, A., Mazumdar, T. and Raj, S.P., 2003, Indirect network effects on product attributes. Marketing Science, 22: 209-221.

Bohlin, E., Bjorkdahl, J. and Lindmark, S., 2003, Strategies for making mobile communications work for europe: Implications from a comparative study. Presented at the European Ploci Research Conference (EuroCPR), Barcelona, Spain, March 23-25.

Bohlman, J.D., Colder, P.N. and Mitra, D., 2002, Deconstructing the pioneer's advantage: examining vintage effects and consumer valuations of quality and variety. Management Science, 48, 1175-1195.

Bouwman, H., 2003, Designing metrics for business models describing mobile services delivered by networked organizations. Presented at the 16th Bled Electronic Commerce Conference, Bled, Slovenia, June 9-11.

Brousseau, E. and Quelin, B., 1996, Asset specificity and organizational arrangements: the case of the new telecommunications services markets. Industrial and Corporate Change, 5: $1205-1230$.

Brynjolfsson, E. and Kemerer, C.F., 1996, Network externalities in microcomputer software: An econometric analysis of the spreadsheet market. Management Science, 42: 1627-1647. 
Camponovo, G. and Pigneur, Y., 2003, Business model analysis applied to mobile business. Presented at the $\boldsymbol{5}^{\text {th }}$ International Conference on Enterprise Information Systems, Angers, France, April 23-26.

Chandy, R.K. and Tellis, G.J., 2000, The incumbents curse? Incumbency, size and radical product innovation. Journal of Marketing, 64: 1-17.

Doyle, S., 2001, Software review: Using short message services as a marketing tool, Journal of Database Marketing, 8: 273-277.

Dyer, J.H. and Singh, H., 1998, The relational view: Cooperative strategy and sources of interorganizational competitive advantage, Academy of Management Review, 23: 660-679.

Faber, E., Ballon, P., Bouwman, H., Haaker, T., Rietkerk, O. and Stern, M., 2003, Designing business models for mobile ICT services. Presented at the 16th Bled Electronic Commerce Conference, Bled, Slovenia, June 9-11.

Foros, Ø., Kind, H.J. and Sørgard, L., 2001, Hvem vinner når tele og media motes? Aksessleverandørenes strategiske utfordringer. In Ulset, S. (ed.) Fra summetone til informasjonsportal, pp. 93-112, Fagbokforlaget, Bergen, Norway. (In Norwegian)

Foros, Ø., Kind, H.J. and Sørgard, L., 2002, Access Pricing, quality degradation, and foreclosure in the Internet. Journal of Regulatory Economics, 22: 59-83.

Foros, Ø., 2003, Price strategy and compatibility in digital networks. SNF Working Paper no. 39/03, Foundation for Research in Economics and Business Administration, Bergen, Norway.

Frels, J.K., Shervani, T. and Srivastave, R.K., 2003, The integrated networks model: Explaining resource allocations in network markets. Journal of Marketing, 67: 29-45.

Gandal, N., Kende, M, and Rob, R., 2000, The dynamics of technological adoption in hardware/software systems: the case of compact disc players. RAND Journal of Economics, $\mathbf{3 1}$ : 43-61.

Gallaugher, J.M. and Wang. Y.M., 2002, Understanding network effects in software markets: Evidence from web server pricing. MIS Quarterly, 26: 303-327.

Ghosh, M. and John, G., 1999, Governance value analysis and marketing strategy. Journal of Marketing, 63: 131-145.

Gressgård, L.J., Methlie, L.B. and Stensaker, I., 2003, Mobile Internet services: Integration models and structural determinants, SNF-report no. 36/03, Foundation for Research in Economics and Business Administration, Bergen, Norway.

Gupta, S., Jain, D.C., Sawhney, M.B., 1999, Modeling the evolution of markets with indirect network externalities: An application to digital television. Marketing Science, 18: 396-416.

Heide, J.B., 1994, Interorganizational governance in marketing channels, Journal of Marketing, 58: 71.85 .

Henten, A,, Olesen, H., Saugstrup, D. and Tan, S.E., 2003, New mobile systems and services inEurope, Japan and South-Korea. Presented at the Stockholm Mobility Roundtable, Stockholm, Sweden, May 22-23.

Herpen, E. van, Pieters,R., 2002, The influence of expertise on preference for assortment variety: when less variety is better. Advances in Consumer Research, 29: 438-439.

Holbrook, M.B., 1996, Customer value - A framework for analysis and research. Advances in Consumer Research, 23: 138-142.

Höflich J.R. and Rössler, P., 2001, Mobile schriftliche Kommunikation oder: E-Mail für das Handy. Medien \& Kommunikationswissenschaft, 49: 437-461.

Jonasson, A., 2001, Innovative pricing effects: theory and practice in mobile Internet networks. Presented at the Nelson and Winter Conference, Aalborg, Denmark, June 12-15.

Kadiyali, V., Sudhir, K. and Rao, V.R., 2001, Structural analysis of competitive behavior: New empirical industrial organization methods in marketing. International Journal of Research in Marketing, 18: 161.186. 
Kannan, P. K., Mei Chang, A.-M., and Whinston, A. B., 2001, Wireless commerce: Marketing issues and possibilities, Proceedings of the $34^{\text {th }}$ Hawaii International Conference on System Sciences, Computer Society Press, Washington, pp. 1-6.

Katz, M.L. and Shapiro, C., 1992, Product introduction with network externalities. The Journal of Industrial Economics, 40: 55-83.

Lee, Y. and O'Connor, G.C., 2003, New product launch strategy for network effects products. Journal of the Academy of Marketing Science, 31: 241-255.

Leung, L. and Wei, R., 2000, More than just talk on the move: Uses and gratifications of the cellular phone, Journalism \& Mass Communication Quarterly, 77: 308-320.

Liebowitz, S. and Margolis, S., 1998, Network Externality. In The New Palgraves Dictionary of Economics and the Law, MacMillan, UK.

Ling, R., 2001): It is in. It doesn't matter if you need it or not, just that you have it. Fashion and the domestication of the mobile telephone among teens in Norway, Working Paper, Telenor R\&D, Oslo, Norway.

Ling, R., Julsrud, T. and Yttri, B., in press, Nascent communication genres within SMS and MMS." in Harper, R., Taylor, A. and Palen, L (eds.), The Inside Text: Social perspectives on SMS in the mobile age, Kluwer London.

Mathwick, C., Malhotra, N. and Rigdon, E., 2001, Experiential value: conceptualization, measurement and application in the catalog and Internet shopping environment. Journal of Retailing, 77: 39-56.

Methlie, L.B. and Pedersen, P.E., 2002, A taxonomy of intermediary integration strategies in online markets. Presented at the 15th Bled Electronic Commerce Conference, Bled, Slovenia, June 17-19.

Montaguti, E., Kuester, S. and Robertson, T.S., 2002, Entry strategy for radical product innovations: A conceptual model and propositional inventory. International Journal of Research in Marketing, 19: 21-42.

Nicholls-Nixon, C.L. and Wood, C., 2003, Technology sourcing and output of established firms in a regime of encompassing technological change. Strategic Management Journal, 24: 651-666.

Nordman, J. and Liljander, V., 2003, Mobile service quality - a study of contributing factors. Working Paper, Marketing Dep., Hanken Swedish School of Economics and Business Administration, Helsinki, Finland.

Northstream, 2002, Den norska SMS-marknaden. Analyst Report, Northstream AB, Stockholm, Sverige (in Swedish).

Nysveen, H., Pedersen, P.E. and Thorbjørnsen, H., in press, Antecedents of intention to use mobile services: Model development and cross-service comparisons. To appear in Journal of Academy of Marketing Science.

Pedersen, P.E., 2001, An adoption framework for mobile commerce. In Schmid, B., Stanoevska-Slabeva, K and Tschammer, V. (eds.). Towards the E-Society. Kluwer Academic Publishers, Ma., pp. 643-656

Pedersen, P.E. and Nysveen, H., 2003, Usefulness and self-expressiveness: extending TAM to explain the adoption of a mobile parking service. Presented at the 16th Electronic Commerce Conference, Bled, Slovenia, June 9-11.

Porter, M.E., 1985): Competitive Advantage: Creating and Sustaining Superior Performance, The Free Press, NY.

Richardson, J., 1996, Vertical integration and rapid response in fashion apparel. Organization Science, 7: 202-212.

Rochet, J.C. and Tirole, J., 2002, Cooperation among competitors: some economics of payment card associations. RAND Journal of Economics, 33: 549-570. 
Sahay, A. and Riley, D., 2003, The role of resource access, market considerations, and the nature of innovation in the pursuit of standards in the new product development process. Journal of Product Innovation Management, 20: 338-355.

Schilling, M.A., 2003, Technological Leapfrogging: Lessons from the U.S. Video Game Console Industry. California Management Review, 45: 6-32.

Sengupta, S., 1998, Some approaches to complementary product strategy. Journal of Product Innovation Management, 15: 352-367.

Shapiro, C. and Varian, H.R., 1999, Information Rules: A Strategic Guide to the Network Economy, Harvard Business School Press, Boston, Ma.

Siau, K., Lim E.P. and Shen, Z., 2001, Mobile commerce: Promises, challenges, and research agenda. Journal of Database Management, 14: 4-13.

Srinivasan, R., Lillien, G. and Rangaswarny, A., 2002, Technological opportunism and radical technology adoption: An application to e-business. Journal of Marketing, 66: 47-60.

Strand Consult, 2001, Show me the money: Revenue models on the mobile Internet. Analyst Report, Strand Consult, Copenhagen, Denmark.

Stuart, T.E., 2000, Interorganizational alliances and the performance of firms: A study of growth and innovation rates in a high-technology industry". Strategic Management Journal, 21: $791-811$

Taylor, S. and Todd, P.A., 1995, Understanding information technology usage: A test of competing models. Information Systems Research, 6: 144-176.

Timmers, P., 1998, Business models for E-commerce. Electronic Markets, 8: 3-7.

Tversky, A. and Kahneman, D., 1974, Judgment under uncertainty: Heuristics and biases. Science, 211: 1124-1130.

Vesa, J., 2003, The impact of industry structure, product architecture, and ecosystems on the success of mobile data services: a comparison between European and Japanese markets. Presented at ITS 14th European Regional Conference, Helsinki, Finland, August 23-24.

Watson, R. T., Pitt, L. F., Berthon, P., and Zinkhan, G. M., 2002, U-commerce: Expanding the universe of marketing, Journal of the Academy of Marketing Science, 30: 333-347.

Weill, P. and Vitale M.R., 2001, Place to Space. Migrating to E-business Models. Harvard Business School Press, Boston, Ma.

Zahra, S.A. and Nielsen, A.P., 2002, Sources of capabilities, integration and technology commercialization. Strategic Management Journal, 23: 377-398. 